\title{
Influência de formas do relevo em atributos físicos de um latossolo sob cultivo de cana-de-açúcar
}

\author{
Influence of the relief forms on physical attributes of an oxisol cropped with sugarcane
}

\author{
Liziane de Figueiredo Brito ${ }^{1 *}$ Zigomar Menezes de Souza $^{2}$ Rafael Montanari ${ }^{2}$ \\ José Marques Júnior ${ }^{2}$ Disnei Amélio Cazetta ${ }^{1}$ Sérgio Ademir Calzavara ${ }^{1}$ \\ Leyser Oliveira ${ }^{1}$
}

\section{RESUMO}

\begin{abstract}
Os atributos físicos do solo variam em função das formas do relevo e sofrem influência da mineralogia da fração argila e do manejo da cultura de cana-de-açúcar, podendo interferir no processo de compactação do solo. Este trabalho foi realizado com o objetivo de avaliar o estado dos atributos físicos em diferentes formas do relevo em um Latossolo Vermelho eutroférrico argiloso sob cultivo de cana-de-açúcar. A área apresenta duas formas de relevo: uma côncava, que ocorre nas posições mais elevadas, e uma linear, constituída pelos segmentos ombro, escarpa, meia encosta e encosta inferior. As amostras de solo foram coletadas durante o ciclo da cultura, nas camadas de 0,00-0,15m, 0,15-0,30m e 0,30-0,45m, para determinação do teor de matéria orgânica e dos seguintes atributos físicos: densidade do solo, porosidade total, macroporosidade, microporosidade, resistência do solo à penetração e teor de água no solo. A mineralogia mais gibbsítica e o maior teor de matéria orgânica, encontrada na forma de relevo côncava e de segmento ombro, proporciona menores valores de densidade do solo, de resistência do solo à penetração e de microporosidade e maiores valores de macroporosidade e de porosidade total do que a mineralogia mais caulinítica, encontrada nos demais segmentos da forma linear.
\end{abstract}

Palavras-chave: relação solo-paisagem, mineralogia do solo, formas côncava e linear.

\section{ABSTRACT}

The physical attributes of the soil vary according to the relief forms and suffer from the mineralogy of the clay fraction and the management of the sugarcane culture, being able to influence the soil compaction process. This research was developed in Jaboticabal-SP, aiming at evaluating the behavior of physical attributes in different relief forms in an oxisol cropped with sugarcane. The area presents two relief forms (concave and linear), the concave one, that occurs at the highest positions, and the linear one, consisting of shoulder, scarp, stocking lean and inferior lean segments. The samples soil were collected during the sugarcane cycle, in the 0.00$0.15,0.15-0.30$ and 0.30-0.45m layers, for the determination of the organic matter and the following physical attributes: bulk density, total porosity, macro and microporosity, soil penetration resistance and soil moisture. The mineralogy most gibbsitic and the greatest value of organic matter, found in the concave relief form and in the shoulder segment, provide lower bulk density, soil penetration resistance and microporosity values and higher macroporosity and total porosity values when compared with the other segments of the linear form (caulinitic mineralogy).

Key words: soil-landscape relation, soil mineralogy, concave and linear forms.

\section{INTRODUÇÃO}

O solo mantido sob vegetação nativa, de modo geral, apresenta atributos físicos como permeabilidade, estrutura, densidade do solo e porosidade adequados ao desenvolvimento normal das plantas (ANDREOLA et al., 2000). Nessas condições, o volume de solo explorado pelas raízes é relativamente grande. À medida que o solo vai sendo submetido ao uso agrícola, os atributos físicos sofrem alterações geralmente desfavoráveis ao desenvolvimento radicular das culturas.

Com a modernização da agricultura, o tamanho das máquinas e equipamentos e a intensidade de uso do solo têm aumentado. Esse processo não foi acompanhado por um aumento proporcional da largura

\footnotetext{
${ }^{1}$ Programa de Pós-graduação, Departamento de Produção Vegetal, Faculdade de Ciências Agrárias e Veterinárias (FCAV), Universidade Estadual de São Paulo (UNESP), Via de acesso Professor Paulo Donato Castellane, s/n, 14870-900, Jaboticabal, SP, Brasil. E-mail: liziane@fcav.unesp.br.*Autor para correspondência.

Departamento de Solos e Adubos, FCAV/UNESP, Jaboticabal, SP, Brasil.
} 
dos pneus, resultando em aumento das pressões aplicadas sobre o solo e, conseqüentemente, promovendo significativas alterações nos atributos físicos do solo, o que pode causar a sua compactação (STRECK et al., 2004). Solos compactados apresentam alteração em sua estrutura original e, conseqüentemente, decréscimo da porosidade total, da macroporosidade e aumento da densidade do solo, da microporosidade e da resistência do solo à penetração (TAYLOR \& BRAR, 1991; PRADO et al., 2002; SOUZA\&ALVES, 2003).

O manejo correto das culturas pode ser estabelecido quando associado ao local da paisagem, pois a variação de atributos do solo podem ser diferenciadas em cada segmento de uma vertente. MEIRELLES (1998), estudando áreas de Latossolo Vermelho eutroférrico sob várias culturas, identificou, com base nos atributos do solo, grupamentos mais homogêneos relacionados às formas do relevo, independentemente do tipo de manejo, indicando a forte influência das posições geomórficas no condicionamento das variações dos atributos dos solos.

Em geral, os latossolos são caracterizados como tendo um alto grau de estabilidade estrutural, com uma estrutura granular forte, normalmente devido à cimentação das partículas do solo pela ação dos óxidos de ferro. Caulinita, gibbsita, goethita e hematita, em diferentes proporções, são os principais minerais da fração argila dos latossolos brasileiros. FERREIRA et al. (1999), estudando a influência da mineralogia da fração argila em atributos físicos de latossolos, verificaram que latossolos cauliníticos apresentaram maior densidade do solo e menor estabilidade de agregados em água, de macroporosidade e de permeabilidade, quando comparados a latossolos gibbsíticos.

O comportamento diferenciado dos atributos físicos dos solos em diferentes posições da paisagem pode ser entendido por meio da análise de solos nos diferentes segmentos de uma vertente. Um estudo desenvolvido em áreas de latossolo sob cultivo de cana-de-açúcar mostrou maior valor de densidade do solo e de resistência do solo à penetração em segmentos com forma linear, quando comparadas com segmentos de formas côncava e convexa (SOUZA et al., 2004).

Este trabalho foi realizado com o objetivo de avaliar o estado dos atributos físicos em diferentes formas do relevo em um Latossolo Vermelho eutroférrico argiloso sob cultivo de cana-de-açúcar.

\section{MATERIAL E MÉTODOS}

O experimento foi conduzido na Fazenda Santa Isabel, no município de Jaboticabal, localizada no nordeste do Estado de São Paulo, Brasil. As coordenadas geográficas são $21^{\circ} 17^{\prime}$ a $21^{\circ} 18^{\prime}$ de latitude sul e $48^{\circ} 08^{\prime}$ a $48^{\circ} 10^{\prime}$ de longitude oeste, com altitude média de $600 \mathrm{~m}$ acima do nível do mar. O clima da região, segundo a classificação de Köppen, é do tipo mesotérmico com inverno seco (Cwa), com precipitação média anual de $1.400 \mathrm{~mm}$, com chuvas concentradas no período de novembro a fevereiro. O relevo é predominantemente suave ondulado, com declividade média variando de 3 a $8 \%$.

O solo foi classificado como Latossolo Vermelho eutroférrico, textura argilosa (LVef), desenvolvido de alterações de rochas máficas, notadamente do basalto. A caracterização granulométrica dos segmentos estudados é apresentada na tabela 1. A área de estudo está sob cultivo intensivo de cana-de-açúcar há mais de 30 anos. A cultura da cana-de-açúcar encontrava-se no quarto corte e o preparo do solo utilizado no plantio foi o convencional; e a cada 6 anos, a área sofre renovação, com duas gradagens pesadas e abertura de sulcos. $\mathrm{O}$ sistema de colheita utilizado na área de estudo é o mecanizado.

A região foi percorrida para identificação e mapeamento dos modelos de paisagem de maior ocorrência. Deste modo, escolheu-se uma área contínua, caracterizada por apresentar duas formas de relevo, sendo elas côncava e linear, segundo classificação de TROEH (1965). A forma côncava e o segmento ombro ocorrem nas posições mais elevadas (topo da paisagem) e a forma linear na seqüência da encosta, sendo constituída pelos segmentos: ombro, escarpa, meia encosta e encosta inferior, conforme DARLYMPLE et al. (1968), que grada para o aluvião do Rio Mogi-Guaçu (Figura 1). As amostras de solo foram coletadas nas formas de relevo côncava e linear (ombro, escarpa, meia encosta e encosta inferior). Utilizou-se o delineamento experimental em parcelas subdivididas em faixas, sendo os tratamentos principais e secundários constituídos, respectivamente, pelas formas do relevo e profundidades de amostragem, com três repetições para a análise textural, oito para resistência do solo à penetração e cinco para os demais atributos físicos analisados.

As amostras de solo foram coletadas em abril de 2004, durante o ciclo vegetativo da cana-de-açúcar, nas profundidades de $0,00-0,15 \mathrm{~m}, 0,15-0,30 \mathrm{~m}$ e 0,30 $0,45 \mathrm{~m}$. A análise granulométrica foi realizada em terra fina seca ao ar, pelo método da pipeta, utilizando 
Tabela 1 - Granulometria do solo e teor de água no solo no momento da realização do teste de resistência do solo à penetração, em diferentes formas da paisagem e de profundidades de amostragem.

\begin{tabular}{|c|c|c|c|c|}
\hline \multirow{2}{*}{ Tratamento } & \multicolumn{3}{|c|}{ Profundidade } & \multirow{2}{*}{ Média } \\
\hline & $0,00-0,15 \mathrm{~m}$ & $0,15-0,30 \mathrm{~m}$ & $0,30-0,45 \mathrm{~m}$ & \\
\hline \multicolumn{5}{|c|}{ Argila $\left(\mathrm{g} \mathrm{kg}^{-1}\right)$} \\
\hline Côncava & 610 & 610 & 655 & $625 \mathrm{~A}$ \\
\hline Ombro & 576 & 535 & 626 & $579 \mathrm{~A}$ \\
\hline Escarpa & 593 & 627 & 610 & $610 \mathrm{~A}$ \\
\hline Meia encosta & 576 & 576 & 576 & $576 \mathrm{~A}$ \\
\hline Encosta inferior & 606 & 629 & 628 & $621 \mathrm{~A}$ \\
\hline Média & $592 a$ & $595 a$ & $619 a$ & \\
\hline \multicolumn{5}{|l|}{$\mathrm{CV}=6,64 \%$} \\
\hline \multicolumn{5}{|c|}{ Silte $\left(\mathrm{g} \mathrm{kg}^{-1}\right)$} \\
\hline Côncava & 255 & 237 & 202 & $231 \mathrm{~A}$ \\
\hline Ombro & 257 & 293 & 206 & $252 \mathrm{~A}$ \\
\hline Escarpa & 254 & 219 & 239 & $237 \mathrm{~A}$ \\
\hline Meia encosta & 246 & 248 & 253 & $249 \mathrm{~A}$ \\
\hline Encosta inferior & 233 & 212 & 225 & $223 \mathrm{~A}$ \\
\hline Média & $249 a$ & $242 \mathrm{a}$ & $225 \mathrm{a}$ & \\
\hline \multicolumn{5}{|l|}{$\mathrm{CV}=17,90 \%$} \\
\hline \multicolumn{5}{|c|}{ Areia Total $\left(\mathrm{g} \mathrm{kg}^{-1}\right)$} \\
\hline Côncava & 135 & 153 & 143 & $144 \mathrm{~A}$ \\
\hline Ombro & 167 & 172 & 168 & $169 \mathrm{~A}$ \\
\hline Escarpa & 153 & 154 & 151 & $153 \mathrm{~A}$ \\
\hline Meia encosta & 178 & 176 & 171 & $175 \mathrm{~A}$ \\
\hline Encosta inferior & 161 & 159 & 147 & $156 \mathrm{~A}$ \\
\hline Média & $159 \mathrm{a}$ & $163 \mathrm{a}$ & $155 \mathrm{a}$ & \\
\hline $\mathrm{CV}=7,33 \%$ & & & & \\
\hline \multicolumn{5}{|c|}{ Teor de água no solo $\left(\mathrm{g} \mathrm{kg}^{-1}\right)$} \\
\hline Côncava & 305 & 310 & 319 & $311 \mathrm{AB}$ \\
\hline Ombro & 277 & 302 & 324 & $301 \mathrm{~B}$ \\
\hline Escarpa & 325 & 323 & 337 & $328 \mathrm{~A}$ \\
\hline Meia encosta & 296 & 287 & 289 & 291B \\
\hline Encosta inferior & 299 & 298 & 312 & 303B \\
\hline Média & $300 \mathrm{~b}$ & $304 a b$ & $317,80 \mathrm{a}$ & \\
\hline $\mathrm{CV}=9,87 \%$ & & & & \\
\hline
\end{tabular}

Médias seguidas pela mesma letra maiúscula na coluna e minúscula na linha não diferem entre si (Tukey, 5\%).

solução de $\mathrm{NaOH} 0,1 \mathrm{M}$ como dispersante químico e agitação mecânica em aparato rotativo de baixa rotação por 16 horas, seguindo metodologia proposta pela EMBRAPA (1997). Amostras indeformadas foram coletadas em anéis volumétricos de $0,03 \mathrm{~m}$ de altura e $0,048 \mathrm{~m}$ de diâmetro, para a determinação da densidade e da porosidade do solo. A microporosidade foi determinada em mesa de tensão e correspondeu à umidade volumétrica da amostra submetida a uma tensão de -0,006MPa, após saturação (OLIVEIRA, 1968). A porosidade total e a densidade do solo foram obtidas segundo EMBRAPA (1997), e a macroporosidade por diferença entre a porosidade total e a microporosidade.
O teor de água no solo no momento da coleta e da determinação da resistência do solo à penetração foram obtidos pelo método gravimétrico, em amostras deformadas (EMBRAPA, 1997). Para determinação da resistência do solo à penetração, utilizou-se um penetrômetro de impacto modelo IAA/ Planalsucar com ângulo de cone de $30^{\circ}$. A transformação da penetração da haste do aparelho no solo $(\mathrm{cm} /$ impacto) em resistência à penetração $(\mathrm{MPa})$ foi determinada segundo STOLF (1991), pela fórmula:

$$
R=\frac{M g+m g+\left(\frac{M}{M+m} * \frac{M g * h}{x}\right)}{A}
$$




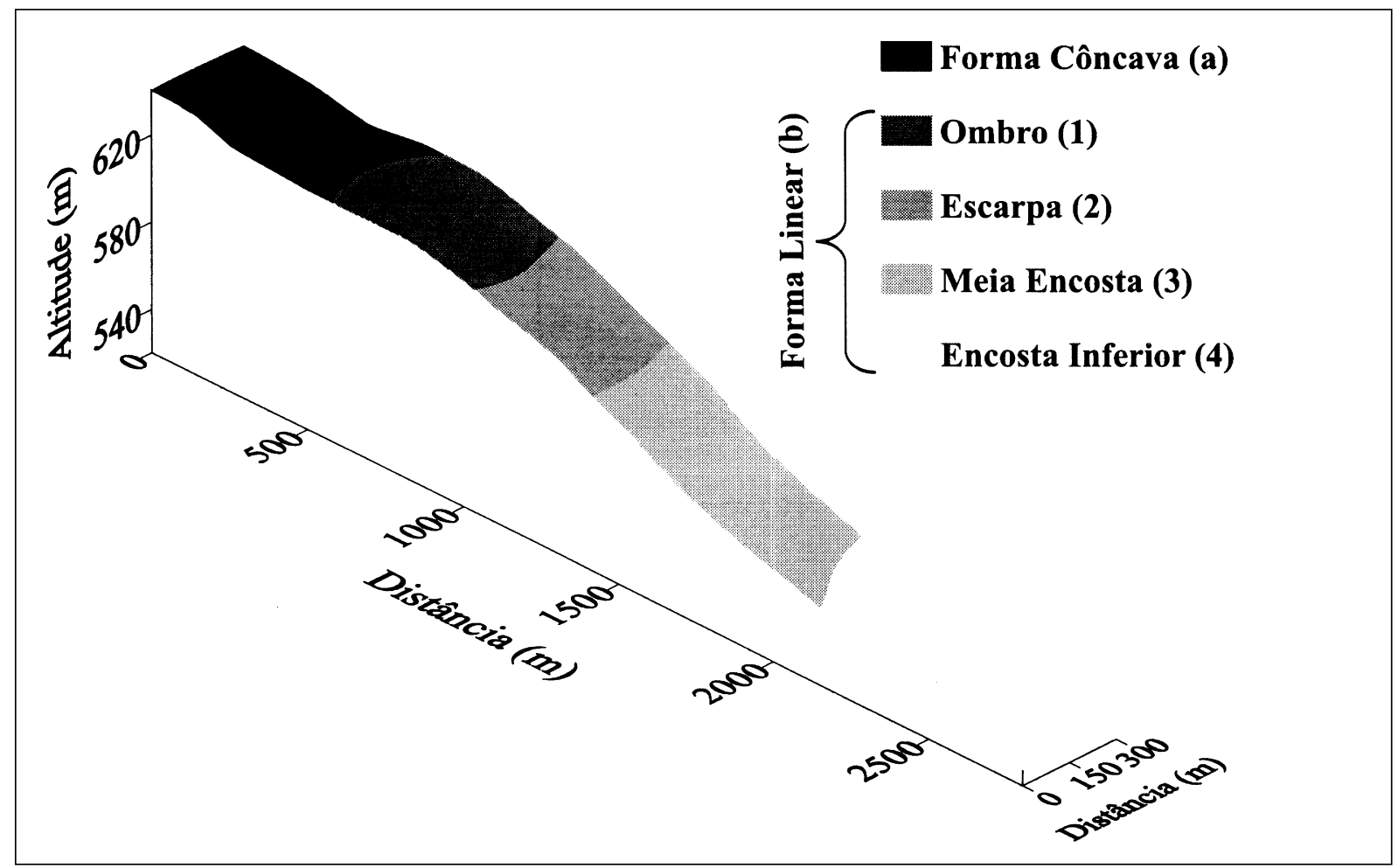

Figura 1 - Modelo digital de elevação da área, com as formas do relevo côncava (a) e linear (b). A pedoforma linear apresenta os seguintes segmentos: (1) ombro; (2) escarpa; (3) meia encosta; (4) encosta inferior.

onde $\mathrm{R}$ é a resistência à penetração, em $\mathrm{kgf}^{-2}(\mathrm{kgf}$ $\left.\mathrm{cm}^{-2} * 0,098=\mathrm{MPa}\right) ; \mathrm{M}$ a massa do êmbolo, $4 \mathrm{~kg}(\mathrm{Mg}-$ $4 \mathrm{kgf}) ; \mathrm{m}$ a massa do aparelho sem êmbolo, $3,2 \mathrm{~kg}$ (mg$3,2 \mathrm{kgf}) ; \mathrm{h}$ a altura de queda do êmbolo $(40 \mathrm{~cm}) ; \mathrm{x}$ a penetração da haste do aparelho (cm/impacto), e A a área do cone $\left(1,29 \mathrm{~cm}^{2}\right)$.

Os valores para a relação $\mathrm{Ct} /(\mathrm{Ct}+\mathrm{Gb})$ foram calculados empregando-se as áreas dos reflexos da Ctcaulinita (001) e Gb-gibbsita (002). Estes foram extraídos de POCAY (2000), que caracterizou mineralogicamente os modelos de paisagem côncavo e linear, nesta mesma área de estudo, na profundidade de 0,60-0,80m.

Os resultados foram analisados estatisticamente com o auxílio do programa SISVAR (FERREIRA, 2000) e, para a análise comparativa das médias, utilizou-se o teste de Tukey ao nível de 5\% de probabilidade.

\section{RESULTADOS E DISCUSSÃO}

O segmento ombro apresentou o maior teor de matéria orgânica em todas as profundidades estudadas, diferindo estatisticamente da forma côncava e de demais segmentos de relevo, com exceção na profundidade de $0,30-0,45 \mathrm{~m}$ (Tabela 2). Os menores teores de matéria orgânica foram encontrados nos segmentos escarpa, meia encosta e encosta inferior, nas profundidades em estudo. Em todas as formas e segmentos de relevo, ocorreu decréscimo do teor de matéria orgânica em profundidade.

Na forma côncava e nos segmentos ombro e escarpa da forma linear, foram encontrados os menores valores de densidade na profundidade de 0,00 $0,15 \mathrm{~m}$ (Tabela 2). Estes resultados provavelmente estão relacionados com a mineralogia mais gibbsítica do solo nestes segmentos (Tabela 3) e ao maior teor de matéria orgânica na forma côncava e no segmento ombro (Tabela 2). Entretanto, estas diferenças não foram observadas nas profundidades de $0,15-0,30 \mathrm{~m}$ e 0,30 $0,45 \mathrm{~m}$.

Os resultados de densidade do solo estão em acordo com os obtidos por SOUZA et al. (2004), que verificaram diferenças deste atributo em superfícies lineares e com curvatura côncava e convexa, os quais variaram entre 1,38 e $1,45 \mathrm{~kg} \mathrm{dm}^{-3}$ na primeira, e entre 1,24 e $1,52 \mathrm{~kg} \mathrm{dm}^{-3}$ na segunda. Valores elevados de densidade do solo mostram o efeito da aplicação de pressões na superfície, por ocasião das operações de cultivo da cana-de-açúcar, sobre os atributos do solo, concordando com SOUZA et al. (2004), que obtiveram valores para áreas com cultivo de cana-de-açúcar acima de $1,35 \mathrm{~kg} \mathrm{dm}^{-3}$ na superfície. HAKANSSON \& 
Tabela 2 - Densidade do solo, porosidade total, macroporosidade, microporosidade, resistência do solo à penetração e teor de matéria orgânica, em diferentes formas da paisagem e de profundidades de amostragem.

\begin{tabular}{|c|c|c|c|c|c|c|c|c|c|}
\hline \multirow{2}{*}{ Tratamentos } & \multicolumn{9}{|c|}{ Profundidade } \\
\hline & \multicolumn{3}{|c|}{$0,00-0,15 \mathrm{~m}$} & \multicolumn{3}{|c|}{$0,15-0,30 \mathrm{~m}$} & \multicolumn{3}{|c|}{$0,30-0,45 \mathrm{~m}$} \\
\hline & \multicolumn{9}{|c|}{ Densidade do solo $\left(\mathrm{kg} \mathrm{dm}^{-3}\right)$} \\
\hline Côncava & 1,25 & B & $\mathrm{a}$ & 1,29 & A & $\mathrm{a}$ & 1,25 & A & $\mathrm{a}$ \\
\hline Ombro & 1,14 & $\mathrm{C}$ & $\mathrm{b}$ & 1,28 & A & $\mathrm{a}$ & 1,31 & A & $\mathrm{a}$ \\
\hline Escarpa & 1,30 & $\mathrm{~B}$ & a & 1,27 & A & a & 1,30 & A & a \\
\hline Meia encosta & 1,38 & A & $\mathrm{a}$ & 1,29 & A & $\mathrm{b}$ & 1,27 & A & $\mathrm{b}$ \\
\hline \multirow[t]{2}{*}{ Encosta inferior } & 1,44 & A & a & 1,27 & A & $\mathrm{b}$ & 1,26 & A & $\mathrm{b}$ \\
\hline & \multicolumn{9}{|c|}{ Porosidade total $\left(\mathrm{m}^{3} \mathrm{~m}^{-3}\right)$} \\
\hline Côncava & 0,46 & $\mathrm{AB}$ & $\mathrm{a}$ & 0,47 & B & $\mathrm{a}$ & 0,49 & A & a \\
\hline Ombro & 0,50 & A & a & 0,48 & $\mathrm{AB}$ & $\mathrm{a}$ & 0,49 & A & a \\
\hline Escarpa & 0,49 & $\mathrm{AB}$ & $a b$ & 0,55 & A & $\mathrm{a}$ & 0,47 & A & $\mathrm{b}$ \\
\hline Meia encosta & 0,51 & A & $\mathrm{a}$ & 0,49 & $\mathrm{AB}$ & $\mathrm{a}$ & 0,46 & A & $\mathrm{a}$ \\
\hline \multirow[t]{2}{*}{ Encosta inferior } & 0,43 & B & $\mathrm{a}$ & 0,48 & $\mathrm{AB}$ & $\mathrm{a}$ & 0,47 & A & $\mathrm{a}$ \\
\hline & \multicolumn{9}{|c|}{ Macroporosidade $\left(\mathrm{m}^{3} \mathrm{~m}^{-3}\right)$} \\
\hline Côncava & 0,12 & A & a & 0,07 & $\mathrm{C}$ & $\mathrm{b}$ & 0,06 & $\mathrm{AB}$ & $a b$ \\
\hline Ombro & 0,15 & A & a & 0,06 & $\mathrm{C}$ & $\mathrm{b}$ & 0,07 & B & $\mathrm{b}$ \\
\hline Escarpa & 0,05 & $\mathrm{C}$ & $\mathrm{b}$ & 0,15 & A & $\mathrm{a}$ & 0,12 & A & a \\
\hline Meia encosta & 0,05 & $\mathrm{C}$ & $\mathrm{b}$ & 0,11 & B & $\mathrm{a}$ & 0,11 & A & $\mathrm{a}$ \\
\hline \multirow[t]{2}{*}{ Encosta inferior } & 0,09 & $\mathrm{~B}$ & $\mathrm{~b}$ & 0,13 & B & a & 0,12 & A & $a b$ \\
\hline & \multicolumn{9}{|c|}{ Microporosidade $\left(\mathrm{m}^{3} \mathrm{~m}^{-3}\right)$} \\
\hline Côncava & 0,34 & B & a & 0,40 & A & $\mathrm{a}$ & 0,39 & A & $\mathrm{a}$ \\
\hline Ombro & 0,35 & B & $\mathrm{b}$ & 0,42 & A & A & 0,41 & A & $a b$ \\
\hline Escarpa & 0,43 & A & a & 0,40 & A & $\mathrm{Ab}$ & 0,35 & A & $\mathrm{b}$ \\
\hline Meia encosta & 0,46 & A & a & 0,38 & A & B & 0,35 & A & $\mathrm{b}$ \\
\hline \multirow[t]{2}{*}{ Encosta inferior } & 0,34 & $\mathrm{~B}$ & a & 0,35 & A & A & 0,36 & A & a \\
\hline & \multicolumn{9}{|c|}{ Resistência do solo à penetração (MPa) } \\
\hline Côncava & 3,12 & A & $\mathrm{b}$ & 4,50 & A & A & 4,37 & A & a \\
\hline Ombro & 1,37 & $\mathrm{~B}$ & $\mathrm{~b}$ & 3,00 & B & a & 3,12 & B & a \\
\hline Escarpa & 3,37 & A & $\mathrm{ab}$ & 3,75 & $\mathrm{AB}$ & a & 2,87 & B & $\mathrm{b}$ \\
\hline Meia encosta & 3,00 & A & $a b$ & 3,75 & $\mathrm{AB}$ & a & 2,87 & B & $\mathrm{b}$ \\
\hline \multirow[t]{2}{*}{ Encosta inferior } & 2,62 & A & $\mathrm{b}$ & 4,25 & A & $\mathrm{a}$ & 4,12 & A & $\mathrm{a}$ \\
\hline & \multicolumn{9}{|c|}{ Teor de matéria orgânica $\left(\mathrm{g} \mathrm{dm}^{-3}\right)$} \\
\hline Côncava & 30,1 & $\mathrm{~B}$ & $\mathrm{a}$ & 21,4 & $\mathrm{~B}$ & $\mathrm{~b}$ & 15,3 & A & $\mathrm{c}$ \\
\hline Ombro & 24,8 & $\mathrm{C}$ & a & 20,1 & B & $\mathrm{b}$ & 14,4 & A & $\mathrm{c}$ \\
\hline Escarpa & 26,3 & $\mathrm{C}$ & $\mathrm{a}$ & 20,2 & B & $\mathrm{b}$ & 14,3 & A & $\mathrm{c}$ \\
\hline \multirow[t]{2}{*}{ Meia encosta } & 23,2 & $\mathrm{C}$ & a & 20,6 & B & $\mathrm{b}$ & 14,6 & A & $\mathrm{c}$ \\
\hline & 35,7 & A & $\mathrm{a}$ & 24,7 & A & $\mathrm{b}$ & 16,2 & A & $\mathrm{c}$ \\
\hline
\end{tabular}

Médias seguidas pela mesma letra maiúscula na coluna e minúscula na linha não diferem entre si (Tukey, 5\%).

VOORHEES (1997) verificaram que, mesmo em sistemas com pouco revolvimento do solo e tráfego de máquinas pesadas, ocorre compactação do solo até $0,4 \mathrm{~m}$.

Na profundidade de $0,00-0,15 \mathrm{~m}$, o ombro e a meia encosta apresentaram valores de porosidade total superiores à encosta inferior (Tabela 2), não diferindo dos demais segmentos. Entretanto, esta tendência não foi verificada na profundidade de $0,15-0,30 \mathrm{~m}$, ocorrendo diferenças entre o relevo côncavo e o segmento escarpa. Observou-se uma redução da porosidade total da profundidade de $0,15-0,30 \mathrm{~m}$ para $0,30-0,45 \mathrm{~m}$ no segmento escarpa.

Nos segmentos escarpa, meia encosta e encosta inferior, cultivados com cana-de-açúcar, verificam-se os menores valores de macroporosidade na profundidade de $0,00-0,15 \mathrm{~m}$, concordando com os maiores valores de densidade do solo e com menores teores de matéria orgânica (Tabela 2). Valores maiores que $0,10 \mathrm{~m}^{3} \mathrm{~m}^{-3}$, considerado como valor mínimo de porosidade de aeração, são necessários ao 
Tabela 3 - Análises mineralógicas da fração argila (DRX) e de suas relações nos solos representativos dos modelos de paisagem estudados, na profundidade de $0,60-0,80 \mathrm{~m}$.

\begin{tabular}{lccc}
\hline Tratamento & $\mathrm{Ct}\left(\mathrm{cm}^{2}\right)$ & $\mathrm{Gb}\left(\mathrm{cm}^{2}\right)$ & $\mathrm{Ct} /(\mathrm{Ct}+\mathrm{Gb})$ \\
\hline Côncava & $0,7-1,2$ & $1,0-1,2$ & $0,37-0,58$ \\
Ombro & 1,2 & 1,0 & 0,53 \\
Escarpa & 1,2 & 1,0 & 0,53 \\
Meia encosta & 1,2 & 0,7 & 0,63 \\
Encosta inferior & 1,4 & 0,2 & 0,87 \\
\hline
\end{tabular}

$\mathrm{Ct}=$ caulinita; $\mathrm{Gb}=$ gibbsita; $\mathrm{Ct} /(\mathrm{Ct}+\mathrm{Gb})=$ relação caulinita/gibbsita.

Adaptado de POCAY (2000)

desenvolvimento do sistema radicular (GUPTA \& ALLMARAS, 1987). Isto também se verifica nos segmentos côncavo e ombro, nas profundidades de $0,15-0,30 \mathrm{~m}$ e $0,30-0,45 \mathrm{~m}$. Apesar de, em algumas situações, o valor obtido ter sido superior a $0,10 \mathrm{~m}^{3} \mathrm{~m}^{-3}$, o maior valor de macroporosidade foi de $0,15 \mathrm{~m}^{3} \mathrm{~m}^{-3}$, o que evidencia o efeito do tráfego de máquinas pesadas nos tratos culturais e, principalmente, na colheita, corroborando os resultados de STRECK et al. (2004). CARVALHO et al. (1991) afirmam que a macroporosidade é o atributo mais afetado pelo cultivo contínuo de cana-de-açúcar.

Analisando a microporosidade nas diferentes formas da paisagem para a profundidade de 0,00-0,15m, observa-se que a escarpa e a meia encosta apresentaram valores maiores em relação aos demais segmentos (Tabela 2). Para as profundidades de 0,15 0,30 m e de $0,30-0,45 \mathrm{~m}$, não foram constatadas diferenças entre as formas da paisagem. Comparando os segmentos de vertente nas profundidades estudadas, observa-se que o ombro diferiu na profundidade de $0,00-0,15 \mathrm{~m}$ da profundidade de $0,15-0,30 \mathrm{~m}$, que a escarpa apresentou maior valor de microporosidade na profundidade de $0,00-0,15 \mathrm{~m}$, em relação à profundidade de $0,30-0,45 \mathrm{~m}$, e que a meia encosta apresentou maior valor em superfície.

Os maiores valores de densidade do solo, na profundidade de $0,00-0,15 \mathrm{~m}$, refletiram-se em menor macroporosidade e em aumento da microporosidade nos segmentos de meia encosta e encosta inferior. Resultados semelhantes foram encontrados por SOUZA (2004), o qual observou melhores condições físicas do solo na forma de relevo côncava e convexa, com mineralogia mais gibbsítica, em relação à forma linear, mais caulinítica.

Com relação aos resultados de resistência do solo à penetração (Tabela 2), o ombro foi o segmento de vertente que apresentou o menor valor, na profundidade de $0,00-0,15 \mathrm{~m}$, diferindo da forma côncava e dos demais segmentos de vertente da forma linear. Houve um aumento de resistência do solo à penetração em profundidade para as formas côncava, ombro e encosta inferior. A identificação de camada compactada a diferentes profundidades, em função do uso e manejo do solo, é quantificada pelos valores maiores que 2,0MPa, limite crítico sugerido por TORMENA (1998), em Latossolo Vermelho eutroférrico.

A resistência do solo à penetração é extremamente dependente do teor de água no solo, com relação inversa, conforme demonstrado por IMHOFF et al. (2001). Entretanto, nas condições de realização do teste, o teor de água não compromete a avaliação de resistência do solo à penetração nas diferentes formas do relevo, visto que, apesar de algumas diferenças entre tratamentos (Tabela 1), o teor de água no solo variou pouco, situando-se entre 277 e $338 \mathrm{~g} \mathrm{~kg}^{-1}$.

Os maiores teores de gibbsita na posição mais elevada da área de estudo (forma côncava e segmento ombro) indicam a presença de solos relativamente mais intemperizados, o que é confirmado pela menor taxa relativa de $\mathrm{Ct} /(\mathrm{Ct}+\mathrm{Gb})$ na forma côncava (Tabela 3). Portanto, de modo geral, a melhor condição dos atributos físicos no segmento ombro e na forma de relevo côncava deve-se provavelmente à influência da gibbsita, concordando com os resultados obtidos por FERREIRA et al. (1999), que encontraram forte influência da fração argila nos atributos físicos de latossolos da Região Sudeste do Brasil, e por SOUZA (2004), que estudou a influência das formas do relevo nos atributos físicos e mineralógicos do solo.

$\mathrm{Na}$ forma de relevo linear, os segmentos escarpa, meia encosta e encosta inferior, onde ocorre um predomínio do mineral de argila caulinita e menores teores de matéria orgânica, a disposição em placas da caulinita pode estar promovendo os maiores valores de densidade do solo, de resistência do solo à penetração e de microporosidade e os menores valores de porosidade total e macroporosidade.

\section{CONCLUSÕES}

A mineralogia mais gibbsítica e o maior teor de matéria orgânica, encontrada na forma de relevo côncava e no segmento ombro, proporcionam menores valores de densidade do solo, de resistência do solo à penetração e de microporosidade e maiores valores de macroporosidade e de porosidade total do que a mineralogia mais caulinítica, encontrada nos demais segmentos da forma linear. 


\section{REFERÊNCIAS}

ANDREOLA, F. et al. Influência da cobertura vegetal de inverno e da adubação orgânica e, ou, mineral sobre as propriedades físicas de uma Terra Rocha Estruturada. Revista Brasileira de Ciência do Solo, Viçosa, v.24, n.4, p.857-865, 2000.

CARVALHO, S.R. et al. Tassement des sols ferrallitiques Podzólico Vermelho Amarelo sous culture de canne a sucre (état de Rio de Janeiro, Brézil): apport d'une analyse de la porosité associée a une connaissance détaillée de la phase minérale. Série Pedologie, Cahiers Orstom, v.26, n.1, p.195212, 1991.

DARLYMPLE, J.B. et al. A hypothetical nine unit land surface model. Geomorphology, v.12, n.1, p.60-76, 1968.

EMPRESA BRASILEIRA DE PESQUISA AGROPECUÁRIA EMBRAPA. Manual de métodos de análise de solo. 2.ed. Rio de Janeiro: Ministério da Agricultura e do Abastecimento, 1997. 212p.

FERREIRA, M.M. et al. Influência da mineralogia da fração argila nas propriedades físicas de latossolos da região sudeste do Brasil. Revista Brasileira de Ciência do Solo, Viçosa, v.23, n.3, p.515-524, 1999.

FERREIRA, D.F. Análises estatísticas por meio do SISVAR (Sistema para análise de Variância) para Windows® ${ }^{\circledR}$ versão 4.0. In: REUNIÃO ANUAL DA REGIÃO BRASILEIRA DA SOCIEDADE INTERNACIONAL DE BIOMETRIA, 45., 2000, São Carlos, SP. Programas e Resumos... São Carlos: UFSCar, 2000. p.255-258.

GUPTA, S.C.; ALLMARAS, R.R. Models to assess the susceptibility of soils to excessive compaction. Advances Soil Science, New York, v.6, n.1, p.65-100, 1987.

HAKANSSON, I.; VOORHEES, W.B. Soil compaction. In: LAL, R. et al. (Eds). Methods for assessment of soil degradation. Boca Raton: Lewis, 1997. p.167-179.

IMHOFF, S. et al. Quantificação de pressões críticas para o crescimento das plantas. Revista Brasileira de Ciência do Solo, Viçosa, v.25, n.1, p.11-18, 2001.

MEIRELLES, H.T. Relações entre superfícies geomórficas, segmentos de vertentes e propriedades dos solos em Batatais, SP. 1998. 118f. Monografia (Graduação em Agronomia) - Universidade Estadual de São Paulo.
OLIVEIRA, L.B. Determinação da macro e microporosidade pela "mesa de tensão" em amostras de solo com estrutura indeformada. Pesquisa Agropecuária Brasileira, Brasília, v.3, n.1, p.197-200, 1968.

POCAY, V.G. Relações entre pedoforma e variabilidade espacial de atributos de latossolos sob cultivo intensivo de cana-de-açúcar. 2000. 177f. Dissertação (Mestrado em Ciência do Solo) - Universidade Estadual de São Paulo.

PRADO, R.M. et al. Sistemas de preparo e resistência à penetração e densidade de um Latossolo Vermelho eutrófico em cultivo intensivo e pousio. Pesquisa Agropecuária Brasileira, Brasília, v.37, n.12, p.1795-1801, 2002.

SOUZA, Z.M.; ALVES, M.C. Propriedades físicas e teor de matéria orgânica em um Latossolo Vermelho de cerrado sob diferentes usos e manejos. Acta Scientiarum, Maringá, v.25, n.1, p.27-34, 2003.

SOUZA, Z.M. et al. Variabilidade espacial de atributos físicos de um Latossolo Vermelho sob cultivo de cana-de-açúcar. Revista Brasileira de Engenharia Agrícola e Ambiental, Campina Grande, v.8, n.1, p.51-58, 2004.

SOUZA, Z.M. Variabilidade espacial e atributos de um latossolo sob diferentes formas do relevo. 2004. $141 \mathrm{f}$. Tese (Doutorado em Produção Vegetal) - Universidade Estadual Paulista.

STOLF, R. Teoria e teste experimental de fórmulas de transformação dos dados de penetrômetro de impacto em resistência do solo. Revista Brasileira de Ciência do Solo, Campinas, v.15, n.3, p.229-235, 1991.

STRECK, C.A.S. et al. Modificações das propriedades físicas com a compactação do solo causada pelo tráfego induzido de um trator em plantio direto. Ciência Rural, v.34, n.3, p.755760,2004

TAYLOR, H.M.; BRAR, G.S. Effect of soil compaction on root development. Soil \& Tillage Research, Amsterdam, v.19, n.2-3, p.111-119, 1991

TORMENA, C.A. Caracterização e avaliação do intervalo hídrico ótimo de um Latossolo Roxo. 1998. 106f. Tese (Doutorado em Solos e Nutrição de Plantas) - Escola Superior de Agricultura Luiz de Queiroz, Universidade de São Paulo.

TROEH, F.R. Landform equations fitted to contour maps. American Journal of Science, New Haven, v.263, n.3, p.616$627,1965$. 